\title{
Madres, pecadoras y obedientes: la formación religiosa de las poblanas en la primera mitad del siglo XIX mexicano*
}

\begin{abstract}
MARIANA MARÍn IBARRA
Afiliada institucionalmente al Instituto de Ciencias Sociales y Humanidades- BUAP (México). Correo electrónico: clasedeetica@hotmail.com. La autora es doctora en educación por la Universidad Autónoma de Tlaxcala (México). Entre sus publicaciones recientes tenemos: "El aprendizaje de los derechos ciudadanos en las amigas poblanas de la primera mitad del siglo XIX a través de los catecismos políticos". En De las rebeliones a los movimientos sociales. Memoria, trayectorias y fuentes sobre la participación de las mujeres en México, coordinado por Elva Rivera Gómez, Gloria A. Tirado Villegas y Ana María del Socorro García García. México: Biblioteca digital de Humanidades, Universidad Veracruzana, 2019 y en coautoría "El Fondo Real de Cholula: digitalización y conservación del patrimonio histórico" en Revista de Conservación y Restauración No. 18 (2019). Entre sus temas de interés se encuentran Mujeres, educación, criminalidad, siglo XIX.
\end{abstract}

Recibido: 17 de junio de 2020

Aprobado: 14 de julio de 2020

Modificado: 31 de julio de 2020

Artículo de investigación científica

DOI: https://doi.org/10.15648/hc.38.2021.2821

Este artículo forma parte del proyecto "Formar madres para construir la nación: la instrucción religiosa femenina en la ciudad de Puebla (1821-1861)" financiado por la Beca de estancia posdoctoral Programa para el Desarrollo Profesional Docente - PRODEP (México).

Esta publicación está bajo una licencia Creative Commons Reconocimiento-NoComercial 4.0

\section{(cc) BY-NC}


Madres, pecadoras y obedientes: la formación religiosa de las poblanas en la primera mitad del siglo XIX mexicano

\title{
Resumen
}

La creación de las culturas escolares femeninas del siglo XIX mexicano se realizó mediante los preceptos pastorales y de gobernanza; las guerras internas e intervencionistas favorecieron discursos de Estado y clericales que optaron por brindar un papel determinante a las poblanas, debido a que la instrucción formal e informal se vio envuelta en una doble exigencia para las mujeres: aspirar a construirse en el estereotipo de la Virgen Concepcionista - la Nueva Eva-, que podía ser pecadora, pero, al mismo tiempo, era susceptible de redimirse mediante la maternidad e instruirse en la escuela formal, para ser siervas temerosas y obedientes.

Palabras clave: educación de las mujeres, religión, ciudad de Puebla, siglo XIX

Mothers, sinners and obedient: The religious formation of the Poblanas in the first half of 19th century in Mexico

\begin{abstract}
The creation of the Mexican nineteenth century female school cultures was carried out through pastoral and governance precepts. The internal and interventionist wars favored state and clerical discourses that chose to offer a decisive role to Puebla women. Formal and informal education was involved in a double requirement for women: aiming at building on the Virgin Conceptionist stereotype - the New Eve- who could be a sinner, but simultaneously susceptible to redeem herself through motherhood and be educated in formal school in order to be faithful and obedient servants.
\end{abstract}

Key words: women education, religion, Puebla city, 19th century.

Mães pecadoras e obedientes: a formação religiosa das poblanas na primeira metade do século XIX mexicano

\section{Resumo}

A criação das culturas escolares femininas mexicanas do século XIX foi realizada através de preceitos pastorais e de governança; as guerras internas e intervencionistas favoreceram discursos estatais e clericais que escolheram fornecer um papel decisivo ao povo de Puebla, porque a educação formal e informal estava envolvida em um duplo requisito para as mulheres: aspirando a construir o estereótipo da 
Virgem Concepcionista — a Nova Eva - que poderia ser uma pecadora, mas ao mesmo tempo era suscetível de se redimir pela maternidade e educar-se na escola formal, para ser serva temerosa e obediente.

Palavras-chave: educação da mulher, religião, cidade de Puebla, século XIX.

Mères, pécheuses et obéissantes : la formation religieuse des femmes de Puebla dans la première moitié du XIXème siècle mexicain.

\section{Résumé}

La création des cultures scolaires féminines mexicaines du XIXe siècle a été conçue à travers des principes pastoraux et du gouvernement. Les guerres internes et interventionnistes ont favorisé les discours de l'état et du clergé, lesquels ont choisi de donner un rôle décisif aux femmes de Puebla, car l'éducation formelle et informelle était impliquée dans une double exigence pour elle: viser à se construire sur le stéréotype de la Vierge Conceptionniste — la Nouvelle Eve- qui pouvait être une pécheuse, mais en même temps capable de se racheter par la maternité et de s'éduquer à l'école formelle, d'être des servantes craintives et obéissantes.

Mots clés: éducation des femmes, religion, ville de Puebla, XIXe siècle.

\section{INTRODUCCIÓN}

La presente investigación tiene como fuentes principales documentos del siglo XIX pertenecientes al Archivo Histórico General Municipal de Puebla, en los que se retoman algunos libros del fondo de expedientes y actas de cabildo, así como impresos decimonónicos pertenecientes a la Biblioteca José María Lafragua; particularmente, se ocupó el fondo de la Academia de Bellas Artes, que resguarda manuscritos en cajas y libros para la enseñanza de las primeras letras.

Metodológicamente, se parte de la epistemología social propuesta por Popkewitz y Brennan¹. Para reconstruir los vacíos historiográficos existentes, es necesario atender el análisis de la creación histórica del conocimiento como forma constituida de razonamiento, afectada por su contexto histórico, social y cultural. Llevar a cabo la epistemología

1 Thomas Popkewitz y Marie Brennan, El desafío de Foucault. Discurso, conocimiento y poder en la educación (Barcelona: Ediciones Pomares- Corredor S.A., 2000), 23. 
social es estudiar tanto el lenguaje como sus efectos de poder en el discurso escolar; en el caso que aquí concierne, reside en considerar al aprendizaje como una práctica social en la que se establece una serie de valores, conocimientos, prioridades y disposiciones sobre el conocer y actuar colectivo; es decir, se deja de lado el aspecto individual.

Dicha construcción de las culturas escolares se relaciona de manera significativa con los conceptos de educación pastoral y gobernanza, enarbolados por Ian Hunter en la creación y desarrollo de un aparato disciplinario y autorreflexivo que obedeció a los intereses del Clero y el Estado $^{2}$. El objetivo de la presente investigación reside en reconstruir el arco cultural edificado a través de la pastoral y gobernanza, creados por la Iglesia y el Ayuntamiento, respectivamente, como parte del marco contextual en que se desarrolló la cultura cívico-religiosa femenina, con lo que se deja de lado la configuración y expresión de la devoción mariana, tema que requeriría un estudio aparte.

Bajo las perspectivas teórico-metodológicas mencionadas anteriormente, se reconstruye el papel que tuvieron las poblanas de la primera mitad del siglo XIX como sujetos dignos de educación y escolarización en la construcción de la nación independiente, pues, al ser consideradas como el núcleo de la célula social familiar, fue necesario su aprendizaje para construir féminas moralmente elevadas y útiles en favor del bien común, tomando como base la construcción ideológica religiosa propuesta por el Clero a través de la Inmaculada Concepción de María. El nuevo enfoque dejó atrás a la Eva pecadora y retomó la construcción de una Nueva Eva, con lo que se creó el estereotipo femenino a partir del virtuosismo de la virginidad que traía consigo la sabiduría en favor de la unidad familiar, núcleo de la incipiente sociedad mexicana.

En primera instancia, se presenta un panorama historiográfico general que menciona algunos estudios sobresalientes respecto a la instrucción formal femenina, así como investigaciones femeninas religiosas que abarcan al clero regular; posteriormente, se establecen los antecedentes del aparato de gobernanza que forjó el Clero y el gobierno desde el

2 Ian Hunter, Repensar la escuela. Subjetividad, burocracia y crítica (Barcelona: Ediciones Pomares, 1998), 92. 
periodo novohispano y que continuará en el periodo independiente bajo el amparo de los Ayuntamientos. Se plantea el contexto social, cultural y educativo de la ciudad Angélica durante la primera mitad del siglo XIX, en el que se desdibuja la línea entre lo sagrado y lo profano, pues la sociedad había interiorizado profundamente su devoción católica, la cual, influenció de forma significativa su vida cotidiana. Finalmente, se profundiza en la construcción simbólica religiosa femenina con la política religiosa de la Nueva Eva.

\section{Acercamientos históricos}

El acercamiento a la historiografía femenina extranjera muestra, para el caso salvadoreño, que el cuerpo femenino, a finales del siglo XIX, fue un territorio en disputa entre los diversos proyectos de nación creados por el Clero y el gobierno, en el que ambas visiones trataron de hacer a las mujeres sus aliadas y la educación les brindó el camino de ingreso al espacio laboral ${ }^{3}$. En Colombia, de 1820 a 1828, el gobierno republicano tuvo diversos obstáculos para la implementación de un sistema educativo en el que se diera enseñanza a las niñas y, por lo tanto, su instrucción quedó en manos del Clero que estableció como objetivo la formación de madres y esposas, lo que perpetuó sus roles tradicionales que desdibujaron los planteamientos de libertad e igualdad enarbolados por la República, y generó un desfase en el sistema curricular que llevaron los varones, quienes pudieron acceder más fácilmente a las ideas de modernidad $^{4}$.

En Francia, se menciona la investigación del caso Sacré-Coeur del último tercio del siglo XIX al siglo XX, en el que a las señoritas se les enseñó latín. Esta propuesta de enseñanza femenina se basó en el pensamiento de que hombres y mujeres podían aprender lo mismo y el colegio ursulino, influenciado por el positivismo y el cientifisismo, apoyó la enseñanza femenina de la lengua, retórica, literatura e historia 5 .

3 Olga C. Vásquez Monzón, “La mujer religiosa, la mujer ilustrada, la mujer ciudadana: representaciones y prácticas femeninas en algunos periódicos salvadoreños, 1871-1889”, Realidad: Revista de Ciencias Sociales y Humanidades No. 135 (2013): 5-34

4 Roger Pita Pico, "De niñas escolares a madres y esposas: restricciones a la educación femenina en Colombia durante la temprana vida republicana, 1820-1828” Revista Interdisciplinaria de Estudios de Género del Colegio de México Vol. 3 No. 5 (2017): 22-56

5 Javier Espino Martín, "Latín y Modernidad en la educación femenina: los colegios del Sacré-Coeur 
La educación femenina europea de los siglos XVI al XIX muestra los aportes realizados por los movimientos renacentistas y de la ilustración que terminaron encasillándolas en preceptos católicos desde la niñez, pues serían las futuras madres que establecerían y difundirían el credo verdadero. Se hacen patentes los espacios femeninos destinados a la educación: la casa, el convento, la escuela elemental, internado laico y escuelas de caridad ${ }^{6}$. También se ha investigado la importancia de la medicina europea y su relación con el cuerpo femenino; la percepción ofrecida es que la mujer se considera un ser incompleto, repleto de imperfecciones físicas que limitan sus capacidades y que tienen como único fin la reproducción ${ }^{7}$.

Tomando en cuenta todo este bagaje europeo y latinoamericano, se muestra que la condición de la educación femenina mexicana no distó mucho de lo ocurrido en otros países, pues la influencia victoriana y clerical, a través de la moral católica, es palpable en las diversas sociedades decimonónicas, en las que el cuerpo femenino es, evidentemente, un cuerpo digno de ser educado para la maternidad.

En México, existen diversas investigaciones que retoman la instrucción femenina; particularmente, se ha profundizado en la importancia y trascendencia de la legislación educativa, así como de la educación formal impartida en escuelas y normales. Respecto a la legislación, María Teresa Yurén Camarena ${ }^{8}$, menciona las grandes diferencias de género existentes en la sociedad patriarcal, que se encargó de motivar la educación femenina para el pensamiento masculino. La Escuela de Artes y Oficios, la Escuela Nacional Secundaria y Escuela Normal para profesoras se abrieron brecha para el desarrollo femenino. En cuanto a la trascendencia de las escuelas normales, el estudio de Oresta López ${ }^{9}$, menciona que las mujeres encontraron en ellas un lugar para desarro-

6 Martine Sonet, "La Educación de una Jóven" en Historia de las mujeres en Occidente, Georges Duby y Michelle Perrot (Madrid: Taurus, 2001)

7 Evelyne Berriot, "El discurso de la medicina y la ciencia" en Historia de las mujeres en Occidente, Georges Duby y Michelle Perrot (Madrid: Taurus, 2001)

8 María Teresa Yurén Camarena, “¿Para qué educar a las mujeres? Una reflexión sobre las políticas educativas del siglo XIX”. En Obedecer, servir y resistir: la educación de las mujeres en la historia de México, María Adelina Arredondo (México: UPN-PORRUA, 2003), 135-149.

9 Oresta López, "Las maestras en la historia de la educación en México", Revista Sinéctica, Vol. 28 (2006): 4-16. 
llarse profesionalmente, pues el Estado o la Iglesia las reconoció como trabajadoras, y ganaron poder y prestigio por medio de su carrera. María del Carmen Gutiérrez ${ }^{10}$, plantea el discurso patriarcal decimonónico, en el que la labor docente se observa desde dos ópticas: como una necesidad para modernizar el país (la liberal) o como un castigo femenino (la conservadora).

$\mathrm{Al}$ abordar los aportes de la instrucción informal femenina, una de las compilaciones forzosas a revisar para la presente temática es la realizada por Adelina Arredondo ${ }^{11}$, dentro de la que Anne Staples ${ }^{12}$ devela el pensamiento decimonónico respecto a la necesidad de educar a las mujeres mexicanas bajo tres premisas: lograr educar a sus hijos en casa, convertirse en mejores compañeras de los hombres en el matrimonio y hacer algo por sí mismas.

Luz Elena Galván Lafarga ${ }^{13}$ observa que, a finales del porfiriato y la etapa revolucionara, existió una preocupación genuina porque las mujeres tuvieran una formación; sin embargo, al egresar, encontraron serias resistencias en el campo laboral. Gloria Tirado Villegas ${ }^{14}$, a partir de la historia social, encuentra diversos espacios femeninos que se afrancesaron gracias a la circulación de ideas promovidas por los medios de comunicación.

La feminización de la profesión docente ha sido un tópico estudiado por diversas historiadoras, quienes han centrado su mirada en aspectos generales de la participación de las mujeres en el ámbito educativo y profundizado en el devenir de las instruidas en la capital del país. Por lo tanto, es importante rescatar la historia regional del inicio de la vida

10 María del Carmen Gutiérrez, "La Escuela Normal para profesoras en el Estado de México. Un espacio para la formación de las mujeres, 1891-1910”. En Estudios históricos sobre las mujeres en México, María de Lourdes Herrera Feria (Puebla: BUAP, 2006), 2227-250.

11 María Adelina Arredondo, Obedecer, servir y resistir: la educación de las mujeres en la historia de México (México: UPN-PORRUA, 2003)

12 Anne Staples, "Una educación para el hogar: México en el siglo XIX”. En Obedecer, servir y resistir: la educación de las mujeres en la historia de México, María Adelina Arredondo (México: UPN-PORRUA, 2003), 85-97.

13 Luz Elena Galván Lafarga, "Historia de mujeres que ingresaron a los estudios superiores, 18761940". En Obedecer, servir y resistir: la educación de las mujeres en la historia de México, María Adelina Arredondo (México: UPN-PORRUA, 2003), 219-243.

14 Gloria A. Tirado Villegas, Hilos para bordar. Acercamientos a las poblanas en el porfiriato (Puebla: Ayuntamiento de Puebla, 2014) 
independiente, con sus consecuentes guerras entre liberales y conservadores e intervenciones extranjeras, hechos que afectaron de manera significativa la formación femenina.

Los grandes esfuerzos que han mostrado la instrucción femenina versan, fundamentalmente, sobre el desarrollo de la enseñanza formal en las escuelas y atienden, en específico, a las normales y sus alumnas. A pesar de que se ha establecido como eje diferenciado entre géneros el curirículum sexuado del siglo XIX, escasamente, se ha profundizado, para el caso poblano, sobre la construcción cultural de la mujer que crearía al ciudadano moderno, a partir de una profunda creencia religiosa que influenciaría a los futuros ciudadanos.

Cuando se alude a la instrucción religiosa femenina, la propuesta poblana historiográfica remite a las diversas investigaciones conventuales que Rosalva Loreto ${ }^{15}$ ofrece. En un estudio de larga duración, muestra la forma en que se construyó y deconstruyó el convento de la Purísima Concepción, el cual se estableció en Puebla desde fechas tempranas y el cual es presentado como un espacio perteneciente a la élite poblana en el que se tejieron relaciones políticas, religiosas y familiares, además de que se garantizó la pureza virginal tanto de sus profesas como de sus niñas educandas. También, analiza la importancia de la pedagogía pastoral que llevaron a cabo las monjas en los conventos, además de resaltar la figura del confesor como maestro y la enseñanza particular de la religiosidad mística y ascética ${ }^{16}$. En el mismo tenor, Nancy Van Deusen $^{17}$ menciona la importancia corporal existente y necesaria para la asimilación del conocimiento que culmina en el acercamiento a Dios mediante el inflamar el corazón de las mujeres piadosas.

15 Rosalva Loreto López, Tota Pulchra. Historia del monasterio de la Purísima Concepción de Puebla, siglos XVI-XIX, (Puebla: BUAP -Educación y cultura, 2017), 226.

16 Rosalva Loreto López, "La didáctica de la salvación femenina. La dirección de espíritus y la cultura de lo escrito". En Historias compartidas. Religiosidad y reclusión femenina en España, Portugal y América. Siglos XV-XIX, María Isabel Viforcos Marinas, Rosalva Loreto López (León y Puebla: Universidad de León y BUAP, 2007), 71-96.

17 Nancy Van Deusen, "El cuerpo femenino como texto de la teología mística”. En Historias compartidas. Religiosidad y reclusión femenina en España, Portugal y América. Siglos XV-XIX, María Isabel Viforcos Marinas, Rosalva Loreto López (León y Puebla: Universidad de León y BUAP, 2007), 163 176. 
García Ugarte y Rosas Salas, en La Iglesia católica en México desde sus historiadores (1960-2010), realizan un importante balance historiográfico sobre los estudios de la Iglesia en México. Afirman que los análisis sobre el siglo XIX enfatizan los conflictos generados por la reforma liberal, al analizar la historia política y social, las relaciones con el Estado mexicano y Roma, y la primera reforma liberal. La virgen de Guadalupe ha sido eje de análisis históricos nacionales y extranjeros que han profundizado desde distintas ópticas: sociales, artísticas, políticas, etc. Sin embargo, escasamente, se han abordado otras representaciones marianas, mientras en el campo educativo, se ha profundizado en la instrucción formal de los religiosos ${ }^{18}$.

Por lo tanto, la historiografía de la educación religiosa femenina poblana ha visibilizado a las regulares que habitaron los conventos, quienes han sido su claro objeto de estudio; sin embargo, falta profundizar en los constructos ideológicos, culturales y religiosos que influenciaron la vida de las mujeres seglares, las cuales vivieron en espacios donde se desdibujó la diferencia entre lo sagrado y lo profano.

\section{AnteCedentes: la CREACión del paCto mediante los Corpa}

El periodo novohispano creó, mediante un aparato jurídico administrativo sólido, el marco normativo en que se movieron los diversos actores que participaron del tiempo y espacio de la Nueva España. Es, en dicho marco contextual, que se forjaron ideales de justicia y salvación colectivos, lo que, en nombre del bien común, estrechó los lazos de actores individuales en favor de una colectividad, y la participación social se realizó en los términos estipulados por la doctrina jurídica de los $\operatorname{Corpa}^{19}$.

Tanto el buen orden como la obediencia fueron preceptos que las congregaciones enarbolaron para la salvación y prosperidad de todos; por lo tanto, mientras el Estado se mostró como una suma de repúblicas

18 Marta Eugenia García Ugarte y Sergio Francisco Rosas Salas, "La Iglesia católica en México desde sus historiadores (1960-2010)", Anuario de historia de la Iglesia Vol. 25 (2016): 147

19 Annick Lempériére, Entre Dios y el rey: la república. La ciudad de México de los siglos XVI al XIX (México: Fondo de Cultura Económica, 2013), 26. 
que tuvieron como cabeza rectora al rey, el Clero desplegó una fuerte estructura compuesta por diversas congregaciones seculares, regulares, piadosas y educativas ${ }^{20}$. De tal manera que las dimensiones del espacio temporal y el espiritual se desdibujaron en favor del bien común. De ahí que la utilidad y la caridad fueran los ejes principales que rigieron las preocupaciones de los aparatos de gobernanza y disciplina: Clero y Ayuntamiento, pues la caridad se convirtió también en una justificación moral.

En lo particular, la enseñanza en las amigas durante el siglo XIX se desarrolló, justamente, bajo el discurso pedagógico de "queremos en nuestra enseñanza ilustrar el entendimiento de nuestras discípulas con la antorcha de las ciencias útiles y prácticas, y al mismo tiempo formar sus corazones con las sublimes verdades de la religión y las virtudes de la moral divina" 21 , en el que enfatizan los principales postulados de los corpa.

La actividad corporativa se hizo presente en la construcción del aparato educativo poblano. En palabras de Ian Hunter, es esta compleja amalgama en la que surge la burocracia pastoral, la cual es un "híbrido de dos tecnologías de la existencia radicalmente autónomas: un aparato de gobierno que buscó la transformación social de la ciudadanía, de acuerdo con los objetivos del Estado; y un sistema de disciplina pastoral que funcionó inculcando los medios de autorreflexión y el autocultivo éticos"22. Estos dos últimos fueron los ejes más destacados para la instrucción femenina.

La formación y organización religiosa se insertó de forma significativa en el devenir del Estado mexicano y la escolarización de las mujeres en las amigas, particularmente en la ciudad de Puebla, atendió la instrucción de ellas para que, al convertirse en madres, forjaran a los futuros ciudadanos. Se tenía así una escuela en cada casa. El siglo XIX mexicano se

20 Annick Lempériére, Entre Dios y el rey: la república, 39.

21 Archivo Histórico General Municipal de Puebla (AHGMP), fondo Antiguo, volumen 71, sección de Expedientes, f. 82.

22 Ian Hunter, Repensar la escuela. Subjetividad, burocracia y crítica (Barcelona: Ediciones Pomares, 1998), 92. 
convirtió en el momento propicio para la instrucción femenina, debido a que, desde las Cortes de Cádiz se establecieron los nuevos preceptos de la nación ilustrada que se oponía a la invasión francesa. Cada género y clase social apoyaba al rey desde su trinchera.

El Ayuntamiento poblano, como institución encargada de favorecer la libertad del pueblo y la instrucción pública, creó sus propios mecanismos ideológicos respecto a la educación femenina. En el discurso de José Ignacio del Pozo director del Colegio de la Purísima Concepción, se muestra la posición de la sociedad respecto a las féminas poblanas y la importancia de su instrucción. Ahí se estipula que "la mujer instruida honra una nación y aumenta por medio de su civilización el espíritu público, y este espíritu es el alma de las naciones, su origen es el cuerpo Municipal por sus atribuciones y su término el Estado"23, y, como se puede observar, el vocabulario religioso se halló íntimamente ligado al desarrollo de las primeras letras en las escuelas femeninas poblanas.

Fue entonces que las cortes proporcionaron postulados específicos respecto a la construcción del ciudadano y la educación, pues a pesar del cisma socio-político, el concepto del bien común fue una constante en los libros autorizados por el Ayuntamiento poblano, los cuales se enseñaron tanto en las escuelas de varones como en las amigas, instituciones en las que se ratificó la importancia de la religión católica bajo el postulado de que solo el catolicismo "protege las leyes sabias y justas... por convenir al bien y concordia del estado la unidad de sentimientos religiosos, así como conviene la unidad de sentimientos políticos"24.

La construcción del Estado católico forjado desde el periodo novohispano presentó dificultades, pues los conflictos del Estado confesional se hicieron patentes "en materia del patronato, la justicia real y la inmunidad eclesiástica, las jurisdicciones eclesiástica y civil, el ejercicio de autoridad local, así como las finanzas eclesiásticas" ${ }^{25}$, por

23 AHGMP, fondo Antiguo, volumen 71, sección de Expedientes, f. 36.

24 "Catecismo político agregado a la Monarquía Española para la ilustración del pueblo, instituciones de la juventud y uso de las escuelas de primeras letras" (Gerona, 1820) en Biblioteca José María Lafragua (BJML), fondo Academia de Bellas Artes, sección Junta de Caridad, f. 10.

25 Brian Connaughton, "La problemática y óptica historiográfica", en México durante la guerra de Reforma. Iglesia, religión y leyes de reforma (Tomo 1), coordinadores Brian Connaughton y Celia del 
lo tanto, la construcción del Estado y el proceso de secularización mostraron una serie de tensiones políticas y sociales; sin embargo, la vida pública combinó el ambiente religioso con la construcción de la nueva civilidad, pues los ritos públicos presentaron actos religiosos, mismos que formaron parte del sistema escolar que fomentó valores sociales compartidos basados en una profunda moral religiosa.

Se creó una cultura mexicana con la articulación de las "estructuras mentales de la sociedad", basadas en los nuevos rituales e instituciones liberales y la predicación religiosa amalgamó la idea de nación mexicana, concepto que devino un vínculo colectivo de unión y pertenencia ${ }^{26}$. La construcción de los Estados-Nación del siglo XIX obedeció al reconocimiento de una profunda religiosidad, con la que se creó un vínculo fuerte entre la Iglesia y el Estado, en el que el Clero se convirtió en parte fundamental de la burocracia del Estado, lo que situó al catolicismo en la base de la construcción nacional. Se creó así un complejo entramado social donde religiosos y civiles se apoyaron para el beneficio común.

\section{Tejiendo la red de la estructura educativa}

Los tiempos de relativa paz fueron aquellos que lograron comenzar a cimentar las bases de la enseñanza pública y gratuita llevada por el Ayuntamiento poblano, es decir, los que abarcaron 1820 a 1840, periodo en el que las nuevas escuelas se amalgamaron con aquellas nacidas desde el seno de la Iglesia, que vieron por la educación de la población menesterosa, además de conjugarse con las llevadas por los civiles como fue la Junta de Caridad. Se creó así una labor conjunta entre Clero y Ayuntamiento para el fomento de la enseñanza gratuita.

Aunque si se realiza un balance entre las escuelas creadas por el Estado, estas son escasas, lo que limitó su nivel de impacto en la población en tanto que el Clero demuestra una estructura fuerte que evidencia no

26 Pablo Mijangos y González, Clemente de Jesús Munguía y el fracaso de los liberalismos católicos en México (1846-1861), en México durante la guerra de Reforma. Iglesia, religión y leyes de reforma (Tomo 1), coordinadores Brian Connaughton y Celia del Palacio Montiel (Xalapa: Universidad Veracruzana, 2011), 174-175. 
solo el sostenimiento de escuelas de primeras letras por tres siglos del periodo novohispano, sino también la fuerza para mantenerlas durante, al menos, la primera mitad del periodo independiente, haciéndose presente a través de organizaciones "civiles" caritativas, como la Junta de caridad.

Los espacios escolares llevados por el Ayuntamiento se encontraron compartiendo con espacios religiosos -tomando en cuenta que algunas de ellas surgieron con ayuda del Clero desde el periodo novohispano- de tal manera que, la instrucción impartida, seguramente, se halló inmersa en tales preceptos, como las ubicadas al costado de la iglesia de Xonaca, la del Santo Ángel o la del Seminario, a pesar de ser públicas, e incluso, los mismos nombres de las escuelas demuestran este pensamiento al identificarse como Nuestra Señora de los Gozos, Nuestra Señora de la Luz o por el hecho de que los directivos que las encabezaron, en algunos casos, fueron religiosos, como sucedió con el caso del rector de Nuestra Señora de los Gozos.

El Estado fomentó la construcción femenina del "Ángel del Hogar" basada en las funciones biológicas de las mujeres. Su capacidad de reproducción debía ser controlada por una línea familiar patrilineal, asegurada mediante mecanismos de encierro y el ejercicio de conductas adecuadas a la civilidad victoriana, basados en la honra y la virtud. Por lo tanto, las mujeres podían seguir dos caminos: o bien el convento, o bien el matrimonio. El segundo era la disculpa divina a la concupiscencia y se lograba la gracia celestial al entrar en estado de gracia y formar una familia. Así, la instrucción femenina buscó ilustrar a las madres para que ellas fueran maestras de sus hijos y se convirtieran en un modelo a seguir. Estas ideas empataron a la perfección con la creación religiosa de la Nueva Eva, como se verá más adelante.

En Puebla, la labor de los buenos ciudadanos de la Junta de Caridad se hizo visible en la enseñanza de primeras letras, pues abren dos escuelas más en 1813: una para niños y otra para niñas. La importancia de las obras realizadas por la Junta es significativa, ya que el ayuntamiento 
poblano no solo aprobó la creación de las escuelas, sino que se encargó de apoyar económicamente su creación y mantenimiento ${ }^{27}$.

La necesidad de instruir a las mujeres se hizo patente en el desarrollo del aparato institucional creado por el Clero, pues, desde inicios de siglo, se estipuló la necesidad de crear escuelas para niñas dentro de los conventos poblanos. Es entonces que surgieron por demanda real y papal los colegios para la enseñanza femenina de las primeras letras. Tales preceptos quedaron estipulados en el reglamento para las escuelas gratuitas de niñas educandas, establecidas en los conventos de religiosas de la Puebla de los ángeles en diciembre de 1818, y en los que el obispo Antonio Joaquín Pérez instituye los ejes del currículum femenino:

\begin{abstract}
"Qué es lo que se os pide cometiendo á vuestro cuidado la educación de las niñas pobres y desvalídas? Que las instruyais en la doctrina cristiana, de la que depende el exercicio reflexivo de la religion y buenas costumbres; que las enseñéis á leer, a escribir, a coser al menos en blanco; cosas todas que asi como en su mayor, ó menor perfeccion realzan los atractivos y constituyen diversos grados de utilidad en la vida civil de las mugeres; al mismo modo su total ignorancia raras veces deja de influir en una relaxacion de las costumbres que deshonra á la humanidad"28.
\end{abstract}

El reglamento muestra con claridad los objetivos perseguidos por la escuela para la enseñanza femenina, es decir, formar mujeres que en primer lugar sean moralmente sobresalientes mediante el ejercicio de la religión católica; en una segunda instancia, se les instruiría en las actividades consideradas como mujeriles: coser y bordar para la elaboración de prendas mientras se justificaba su importancia y utilidad; finalmente, se recalcaría la importancia de la moralidad mediante el ejercicio público de las buenas costumbres que brindaban la honra no solo familiar, sino de toda la humanidad, principio de las naciones cultas y modernas. De tal forma que, desde la perspectiva del obispo Pérez,

27 Salvador Cruz, Historia de la educación pública en Puebla 1790-1982 (Puebla: BUAP, 1995), 47.

28 "Reglamento para las escuelas gratuitas de niñas educandas, establecidas en los conventos de religiosas de la Puebla de los ángeles" (Puebla, 1818) en BJML, fondo Academia de Bellas Artes, sección Junta de Caridad, f. 1. 
"la buena educación es el primer título que introduce á las mujeres y hace que sean mejor recibidas en la sociedad". De ahí la importancia de instruir a la juventud femenina ${ }^{29}$. La enseñanza religiosa que se dio en los conventos fue la única que, para el caso femenino, atendió a la enseñanza del latín, debido a que, al tomar los hábitos, tanto el canto como el rezo se realizaban en dicha lengua.

Es notable la fuerte articulación de la corporación civil y religiosa desde sus cabezas, es decir, desde el rey y el Papa, debido a que ambos unieron esfuerzos para la creación y sostenimiento de escuelas de primeras letras dentro de los conventos femeninos y masculinos, decretos que se llevaron a cabo según "el tenor de la carta decretoria de S.S. de 15 de Abril de 1816 y de Real cédula de S. M. de 20 de Octubre de 1817"30, en la que se estipuló la necesidad de crear dichas escuelas solo mientras se requiera de mejorar la educación pública.

Ante dicha propuesta también se estableció un currículum específico en el que se les pidió a las religiosas enseñar a las niñas pobres la doctrina cristiana, la reflexión de la religión y buenas costumbres, enseñarles a leer, escribir y coser en blanco con el propósito de volverlas mujeres de utilidad para la vida diaria evitando así la relajación de las costumbres que trae la deshonra de la humanidad.

Analizar el despliegue del aparato normativo institucional religioso es importante, pues la unión del rey y el Papa crearon un arco cultual significativo para la creación del papel de las mujeres que vivieron en los reinos de Indias e islas Filipinas. Para el caso de Guatemala, se ha analizado la educación de las niñas bajo estos postulados que culminaron con la creación de las Constituciones de matronas seculares que destacaron por su excelente organización, reglas claras y precisas con la participación directa de profesoras que, incluso, eran beatas y que recibieron posteriormente el nombre de matronas, de tal forma que,

29 "Reglamento para las escuelas gratuitas de niñas educandas, establecidas en los conventos de religiosas de la Puebla de los ángeles" (Puebla, 1818) en BJML, fondo Academia de Bellas Artes, sección Junta de Caridad, f. 4.

30 "Reglamento para las escuelas gratuitas de niñas educandas, establecidas en los conventos de religiosas de la Puebla de los ángeles" (Puebla, 1818) en BJML, fondo Academia de Bellas Artes, sección Junta de Caridad, f. 7. 
los colegios se caracterizaron por la fiel observancia a la costumbre y prácticas religiosas ${ }^{31}$.

Los miembros del Ayuntamiento poblano se encontraron plenamente impregnados de los preceptos de la religión católica, como quedó demostrado en su actuar cotidiano al participar de las constantes invitaciones a las celebraciones religiosas de las diversas iglesias y conventos de la ciudad. Es necesario puntualizar que, como parte del ritual realizado para la toma de posesión del cargo público del cabildo, se recibió juramento, en el que se ratificó la administración de una justicia recta, el castigo de pecados públicos, evitar las ofensas que se cometan contra Dios, el mantenimiento de la paz y tranquilidad de la República, acompañar el estandarte de la corporación en la procesión del Santo entierro y -particularmente, se enfatiza- el defender el misterio de la Purísima Concepción ${ }^{32}$.

Es entonces, a partir de las actas de cabildo, que se reconoce la gran importancia del misterio de la purísima Concepción para los poblanos, pues incluso sus autoridades gubernamentales juraron defender dichos postulados al convertirlos en el ideal a seguir de las mujeres decimonónicas. Asimismo, tales acciones no son desconocidas dado que la construcción de los funcionarios civiles poblanos atravesó por una formación moral que los autodesignó como supervisores pastorales ${ }^{33}$.

El proyecto político religioso enarbolado por el obispo poblano Francisco Pablo Vázquez y la mitra estableció una generación de renovación, al adecuar sus objetivos a la convicción republicana y la defensa de las libertades de la iglesia católica desde la independencia hasta $1833^{34}$. Así la construcción nacionalista se vio influenciada por los símbolos religiosos, con lo que se generó una fusión entre lo cívico y lo

31 Salvador Cruz, Historia de la educación pública en Puebla 1790-1982 (Puebla: BUAP, 1995), 47.

32 (Puebla, 1817), AHGMP, fondo Antiguo, volumen 86, sección de Actas de Cabildo, fs. 8-9.

33 Ian Hunter, Repensar la escuela. Subjetividad, burocracia y crítica (Barcelona: Ediciones Pomares, 1998), 111.

34 Sergio Rosas Salas, "De la república católica al estado laico: Iglesia, estado y secularización en México 1824-1914", Lusitania Sacra: Revista do Centro de Estudios de Historia Eclesiástica No. 25 (2012): 231. 
religioso y, en palabras de Rosas, un "elemento central para ello fue la homilética y su derivado secular, el discurso cívico" 35 .

Es en los periodos de guerra en los que los discursos de las autoridades eclesiásticas de la ciudad angélica, incitan, en espacios de participación masiva, la creación de los nuevos ciudadanos en defensa de la libertad de la nación mexicana. Particularmente, resalta la actividad militante del clero secular poblano; se observa de forma importante en los discursos del obispo Francisco Pablo Vázquez, quien emitió un discurso dirigido a todos los sacerdotes poblanos para que fuera replicado ante los fieles desde el púlpito, y sobre el que se arengaba a la población para frenar la amenaza de invasión francesa en el puerto de Veracruz. En diciembre del año 1838, el obispo Vázquez arengó a la población a defender la independencia de México, pues

"Acaso en el mayor ardor de la lid nos vá a faltar la protección del Dios de las batallas. Tenemos muchos indicios de que está irritado contra nosotros; porque la mayor mortandad que hemos tenido en estos últimos años, las repetidas desgracias sufridas en nuestros campos, que han hecho mas costosa la subsistencia a la gente miserable, y la temeridad misma de una nación culta en venir, bajo de los mas injustos pretestos a invadir nuestro territorio ¿no están manifestando claramente la ira del cielo?"36.

Tales aseveraciones muestran la compleja situación en que se encontró la ciudad, pues las constantes batallas y la epidemia de cólera que la azotaron, provocaron altos índices de mortandad que desfavorecieron la economía y el desarrollo social, político, cultural y religioso.

Después de la invasión norteamericana, el obispo poblano Pablo Vázquez se encontró profundamente preocupado por la impiedad existente en la sociedad, la cual se traducía en la irreligión e inmoralidad de la feligresía. A sus ojos, había un relajamiento de las costumbres sociales; por ello, se dio a la tarea de reformar las costumbres mediante

36 (Puebla, 1838) BJML, fondo Academia de Bellas Artes, caja 12, sección Junta de Caridad, expediente 2, f.1. 
actividades corporativas: instauró nuevos cultos de mártires romanos, reparó reliquias, mejoró físicamente los templos y el impulso de prácticas devocionales de cofradías y hermandades y, finalmente, el fomento de las misiones (visitas de varios frailes a alguna población para que durante una semana se dedicaran a la predicación, confesión y administración de la eucaristía) $)^{37}$.

Ante el panorama de entonces, el obispo exhortó a las poblanas a defender la patria mexicana desde su pedestal. Particularmente, es de especial interés para Vázquez el combatir lo que en sus palabras estipula como la impiedad y la irreligión, consecuencias inevitables de la furia divina, las cuales, afectaban de manera más puntillosa al sexo "frágil". Dentro de este discurso, el amor romántico es el mecanismo empleado para desarticular las más puras intenciones de las mujeres, pues, mediante la seducción realizada con halagos, dádivas y promesas de amor eterno, se desdibuja el miedo al castigo. Particularmente, es escandaloso para el obispo escuchar en las parejas sobre la inexistencia del infierno y la omisión del castigo que Dios da a los placeres carnales, justificados como un desahogo de la naturaleza ${ }^{38}$.

Las mujeres quedan condenadas al perder el pudor y la modestia, desgraciando su vida y la de otros; sin embargo, el mayor problema es que "pierden la fe que es la mayor desgracia, porque quedan como un caballo fogoso sin freno, ó como un nave sin timon en medio del mar proceloso de este mundo”. En este escenario, solo la oración es la respuesta ante los males que aquejan a la sociedad mexicana y, por lo tanto, Vázquez incita a todas las mujeres a orar, aunque, particularmente, a las religiosas se les arenga de la manera siguiente:

"AAmadas religiosas, esposas de Jesucristo! Las oraciones de las que como vosotras han seguido al Cordero, han salvado muchas veces de mil males á las ciudades. Los que amenazan á nuestra patria en la presente

37 Sergio Rosas Salas, La iglesia mexicana en tiempos de la impiedad: Francisco Pablo Vázquez 1769-1847 (México: COLMICH, BUAP, Eyc, 2015), 288-293

38 Puebla, 1838) BJML, fondo Academia de Bellas Artes, caja 12, sección Junta de Caridad, expediente 2, fs. $1-2$. 
época son gravísimos; nuestra Santa Religión, nuestra independencia y libertad, nuestra existencia, nuestras propiedades, todo se perdería si llegaran a triunfar nuestros invasores. Levantad vuestras inocentes manos al cielo y pedid á vuestro divino Esposo que nos mire con piedad, que olvide nuestras iniquidades, que nos dé la gracia de reconciliación y nos conceda el triunfo; el cual asegurándonos por mucho tiempo la paz, nos haga respetar de otras potencias, que presumiendo de su antigüedad y despreciando nuestra infancia, pretendan sojuzgarnos..."39.

Tales discursos buscaron generar un espíritu cívico en defensa de la patria. Más aún, se exhortó a toda la población a participar para apaciguar la furia divina, asistiendo al novenario de la Virgen de Guadalupe ofrecido en la iglesia del Espíritu Santo, después de que hubiera terminado el que ya se realizaba en la iglesia de Santo Domingo. Se organizaron pláticas por la mañana y noche con el propósito de desenrojar al Dios irritado por las ingratitudes, crímenes y olvido. Se exhortó así a que todas las iglesias parroquiales de la diócesis celebraran un triduo de misas a la Virgen de Guadalupe, en el que se cantó la letanía lauretana, la oración Tempore Belli, y a que se rezara todas las noches en cada familia de diocesanos el santo rosario para ganar entre todos el favor de la intercesión divina de la Guadalupana ${ }^{40}$.

Como se observa, la pedagogía que se realizó en los espacios educativos oficiales y en los públicos se basó en "una improvisación basada en las disciplinas de la guía pastoral cristiana... impulsada por las exigencias de gobierno, y fue puesta en práctica por un poderoso aparato burocrático gubernamental" 41 , que, en el caso poblano, se desplegó a través de diversas corporaciones de caridad que se encargaron de la educación, de tal forma que en una labor conjunta de individuos adinerados, la junta de caridad, hospicios, casas de recogimiento, cárceles, etc. brindaron instrucción para la juventud y adultez desvalida.

39 Puebla, 1838) BJML, fondo Academia de Bellas Artes, caja 12, sección Junta de Caridad, expediente 2, f. 4.

40 Puebla, 1838) BJML, fondo Academia de Bellas Artes, caja 12, sección Junta de Caridad, expediente 2, f. 8.

41 Ian Hunter, Repensar la escuela. Subjetividad, burocracia y crítica (Barcelona: Ediciones Pomares, 1998), 92. 


\section{El arribo de la NUEva Eva}

La práctica religiosa aprobada por Roma se había intentado realizar desde el periodo novohispano. Para 1835, Gregorio XVI autorizó a los obispos mexicanos reducir el número de fiestas religiosas e importancia de los santos. Tales cambios trajeron descontento entre los fieles y, a pesar de las instrucciones papales, años más tarde se siguieron presentando dudas respecto a la socialización en las fiestas religiosas, pero el llamado papal atendió a la mesura y a limitar la celebración. En esta sociedad significativamente influenciada por el catolicismo, Roma marcó los destinos de su feligresía; sin embargo, la gobernanza de los políticos mexicanos creó una serie de tensiones entre la relación IglesiaEstado, debido a que, desde 1835 y hasta 1850, las gestiones de los diplomáticos mexicanos en la Santa Sede tuvieron como resultado la reducción del diezmo a la mitad, actitud que se justificó con las carencias agrícolas o guerras sociales. Incluso, con el gobierno de Santa Ana, se solicitó a Roma la necesidad de reformar al clero regular para que se sometieren a la autoridad episcopal el uso del diezmo para socorrer a los párrocos, y también se llegó a pedir una reglamentación para los protocolos cívico-religiosos, con el objetivo de homologarlos a Roma y dejar las arbitrariedades del clero mexicano, con lo que se selló el pacto entre Iglesia y Estado ${ }^{42}$.

La presencia de la virgen en sus diversas advocaciones fue una constante desde el periodo novohispano; de hecho, existen diversas investigaciones al respecto; sin embargo, para la temporalidad de la presente investigación, se retoma la trascendencia de la virgen en el proceso independentista, ya que los españoles retomaron, como parte de su causa, a la Virgen de los Remedios, mientras que los insurgentes llevaron el estandarte guadalupano. Cabe destacar que el uso de las advocaciones obedeció a las prácticas locales ${ }^{43}$. La gran influencia del guadalupanismo se ha observado a partir de los sermones impresos y

42 Brian Connaughton, "La "Metamorfosis en nuestra nación". Iglesia y religiosidad en México: 18361855”, Revista de Estudios Históricos INAH No. 89 (2019): 83-84 y 87.

43 Brian Connaughton, "De la monarquía a la nación en la América española: las disonancias de la fe", en La Iglesia en Nueva España. Problemas y perspectivas de investigación, coord. María de Pilar Martínez López-Cano (México: Universidad Nacional Autónoma de México, Instituto de Investigaciones Históricas, 2010), 398. 
manuscritos, así como en la importancia que tuvo en el culto nacional a través del proyecto pastoral del arzobispo Pelagio, Antonio de Labastida y Dávalos (obispo poblano) ${ }^{44}$.

Las celebraciones cívico religiosas se establecieron mediante los decretos de las élites religiosas. Su mayor exponente fue el Papa. La sociedad poblana de la ciudad aprehendió los preceptos de la misión pastoral y las mujeres solo tuvieron cabida como madres de familia. La creación del dogma sobre la inmaculada concepción fue profundo y se vio reiterado y reforzado por diversos milagros acontecidos desde inicios del siglo XIX, los cuales volcaron su fe hacia la devoción mariana siendo sus principales precursores los papas Pío VII (1800) y León XII $(1878)^{45}$.

Por lo tanto, a pesar de que el culto hacia la Inmaculada Concepción se estableció desde el periodo novohispano auspiciado por el Rey y los franciscanos, para el siglo XIX, el Papa auspició su devoción, la cual fue retomada por los poblanos y la cual se enmarcó como modelo femenino y de protección de la iglesia atacada por la impiedad, pero de una Iglesia Universal que se encuentra perseguida ${ }^{46}$. Así, tanto las religiosas de los conventos como las mujeres seculares debían rezar para ponerse bajo el amparo de la Total Pulchra.

En dicho contexto religioso es que el papa Pío IX, en 1848, se encargó de realizar una Comisión constituida por veinte teólogos encargada de estudiar la definibilidad de la verdad sobre la inmaculada concepción y se les hizo votar al respecto, lo que dio como resultado, un año más tarde, la encíclica Obi Primum, en la que se pidió la opinión respecto a la conveniencia de dicho dogma a todo el episcopado. Ante tal encomienda se obtuvo como votación final 546 votos a favor y solo 57 presentaron objeciones ${ }^{47}$.

44 Marta Eugenia García Ugarte y Sergio Francisco Rosas Salas, La Iglesia católica en México, 115.

45 Juan Luis Bastero, "La inmaculada concepción en los siglos XIX y XX", Anuario de Historia de la Iglesia No. 4 (2004): 79-102.

46 Conferencia: Jesús Joel Peña Espinosa, Vivir la fé perseguidas: las Agustinas Recoletas de Puebla en los siglos XIX y XX, Museo de Arte Religioso ex Convento de Santa Mónica, Puebla, INAH, 17 de Julio de 2020

47 Juan Luis Bastero, La inmaculada concepción, 79-102. 
A partir del pontificado de Pío IX se establecieron una serie de reformas que encaminarían a la Iglesia mexicana al proyecto de romanización, en el cual se fortaleció la autoridad de la jerarquía romana y el Papa se afianzó por encima de los poderes locales. Para lograr dicho cometido, se estableció “a) la reforma del clero y de las instituciones eclesiásticas; b) el establecimiento de un nuevo tipo de relaciones con el poder civil que le permitiera frenar el impacto de las reformas liberales, y c) el aumento del respaldo de la feligresía"48, además de que se creó el Colegio Pío Latinoamericano en 1858.

Al profundizar respecto al mensaje exhibido en la bula, se muestra que mediante la reinterpretación de textos bíblicos, los teólogos brindaron un nuevo carácter a María, por el que se sugiere su comparación con Eva; sin embargo, no es un contraste entre la mujer virginal y la pecadora; por el contrario, es una simbiosis entre ambos personajes:

“... para defender la original inocencia y santidad de la Madre de Dios, no solo la compararon muy frecuentemente con Eva todavía virgen, todavía inocente, todavía incorrupta y todavía no engañada por las mortíferas asechanzas de la insidiosísima serpiente, sino también la antepusieron a ella con maravillosa variedad de palabras y pensamientos. Pues Eva, miserablemente complaciente con la serpiente, cayó de la inocencia original y se convirtió en su esclava; mas la santísima Virgen, aumentando de continuo el don original, sin prestar jamás atención a la serpiente, arruinó hasta los cimientos su poderosa fuerza con la virtud recibida de lo alto" ${ }^{\prime 4}$.

Las nuevas interpretaciones sobre María abrieron la puerta para convertirla en una nueva Eva, una Eva primigenia que no había sido influenciada por el pecado y que en su carácter de inocencia podía ser inmaculada, lo que incluía lo inmaculado del pecado original. Asimismo, existe una relación simbiótica entre Cristo y su madre que atiende a la concepción, puesto que el Verbo moldeó el seno materno para que el hijo creciera

48 Cecilia Adriana Bautista García, Hacia la Romanización de la Iglesia Mexicana a fines del siglo XIX, Historia Mexicana Vol. 55 No. 1 (2005): 105-106.

49 Juan Luis Bastero, La inmaculada concepción, 79-102. 
sin mácula, de modo que se convirtió a María, de igual manera, en un fruto de Cristo.

A pesar de las grandes muestras de fe y aprobación por parte de la comunidad católica, el Concilio Vaticano I desestimó el dogma de la Inmaculada Concepción, debido a que se estableció la premisa de que el único que goza de la concepción sin pecado es Cristo, verdad establecida durante los primeros trece primeros siglos del catolicismo. A pesar de ello, la gran aceptación y extensión del culto mariano se hizo presente incluso dentro de la misma iglesia Católica.

Particularmente en la ciudad de Puebla, se creó gran algarabía para acoger la oficial celebración de la inmaculada Concepción, pues como se mencionó en capítulos anteriores, ya existía en la población gran fervor al culto concepcionista, el cual encontró en la comunidad de pobladores de la ciudad angélica un espacio propicio para su desarrollo pues desde los miembros del cabildo hasta los religiosos acogieron con regocijo la noticia. De ahí que la comunidad católica vertió su entusiasmo en celebraciones, sermones y cartas pastorales, todo ello difundido mediante la oralidad de los religiosos y la palabra escrita mediante la revista eclesiástica.

Profundizando en las celebraciones, fue el convento de la Purísima Concepción de Puebla el que fungió como un lugar privilegiado del mundo urbano, pues las expresiones de fervor dieron prestigio al convento que forjó alianzas con otras iglesias. El 19 de mayo de 1855 la comunidad de la ciudad angélica participó activamente de las celebraciones; se construyó una portada en forma de mansión para la imagen, se cantó con orquesta en el responsorio, se realizó una procesión donde participaron diversas comunidades eclesiásticas y todos los fieles llevaron una vela encendida además de la celebración de diversas misas.

Los festejos duraron varios días y fueron actos cívico-religiosos gracias a la participación de representantes del poder laico, y de autoridades gubernamentales y eclesiásticas: 
"Las fiestas por la promulgación pontificia del dogma de la Inmaculada, tuvieron tres aspectos notables: fortalecieron la presencia del catolicismo en la República mexicana, pues retomaron un culto que había tenido un arraigo desde la era novohispana; entrelazaron las relaciones de los gobiernos a todos los niveles con la Iglesia y proyectaron la participación de grupos sociales letrados a través de esta actualización del culto" ${ }^{\prime 50}$.

Es importante reconocer los cultos religiosos que impregnaron la enseñanza de las mujeres poblanas, pues, tomando en cuenta la gran influencia en la instrucción católica ejercida mediante las enseñanzas familiares, escolares y culturales, el manejo del tiempo educativo se encontró influenciado de forma significativa por el culto de los rituales sociales y académicos, pues al encontrarse las escuelas cerca o dentro de los conventos, el tiempo sagrado hizo su participación en la instrucción femenina del siglo XIX.

De tal forma que la escuela se encargó de crear una pedagogía pastoral mediante la "geometría del recuerdo" que se expresa en "formas materiales que estructuran la mirada de quienes bajo sus muros y techos habitan, enseñan, estudian y conviven, dotando de sentido a la experiencia que se construye bajo su silencioso influjo" "51. La instrucción pastoral encaminada a la enseñanza femenina, en la que los ejercicios de lectura duraron tres horas por la mañana y dos en la tarde, en los meses de junio, julio, agosto y septiembre. Debido a la temporada de lluvias, se aumentaba media hora en las mañanas y desaparecían las clases vespertinas. Por supuesto, los rituales de las fiestas titulares de cada convento, Semana Santa, víspera de corpus, elección prelada, Día de Todos Santos, la Concepción, natividad, elección prelada y entierro de alguna religiosa fueron motivo de suspensión de clases y, por supuesto, rezar el rosario y pedir por las necesidades de la iglesia y el Estado fue apremiante ${ }^{52}$.

50 Rosalva Loreto López, Tota Pulchra. Historia del monasterio de la Purísima Concepción de Puebla, siglos XVI-XIX, (Puebla: BUAP -Educación y cultura, 2017), 226.

51 Agustín Escolano Benito, Tiempos y espacios para la escuela. Ensayos históricos (Madrid: Biblioteca Nueva, 2000), 46.

52 "Reglamento para las escuelas gratuitas de niñas educandas, establecidas en los conventos de religiosas de la Puebla de los ángeles" (Puebla, 1818) en BJML, fondo Academia de Bellas Artes, sección Junta de Caridad, f. 11. 
Para 1853, Santa Anna decretó que los gobernantes serían los encargados de publicar, difundir y ejecutar las leyes, buscar la protección de personas y bienes, castigar el desacato a la religión, velar por la sanidad, buscar el fomento intelectual y moral, vigilar los ramos que lo requirieran, podían disponer de la fuerza armada, emitir sanciones y multas, creación de estadísticas poblacionales, resguardar de la instrucción primaria y secundaria, decretar penas correccionales, destinar a los vagos a una correccional en el obraje o el campo ${ }^{53}$. Así, la ciudad angélica se convirtió en un conglomerado de ideas cívico-religiosas que determinaron el papel de las mujeres en la vida cotidiana, pues, al amplio fervor concepcionista, se unió, por decreto residencial, el guadalupano.

\section{Conclusiones}

La nueva Eva representada, a través de la Inmaculada Concepción, significó el estereotipo femenino decimonónico al mostrar a la mujer madre de familia; pero, sobre todo, encarnó dos momentos simbólicos: la mujer divina y sabia, de modo que se convirtió en el estereotipo decimonónico por excelencia a seguir para las mujeres poblanas, pues, por un lado, representa la virginidad, familia y buenas costumbres y, por el otro, la sabiduría que le brinda la maternidad y la enseñanza de las primeras letras. El papel social de las mujeres se creó, entonces, para que participaran como soporte fundamental en la construcción de la familia, con lo que se creó, "literalmente" en su vientre, a los futuros ciudadanos del México independiente, para después enseñarles las primeras letras y las buenas costumbres desde el hogar. Se tenía así, una escuela en cada casa.

La escolarización de las masas se forjó a través de este currículum que enarboló los conceptos del bien común, la libertad y moralidad victorianos. Fue entonces que, para las mujeres, se obligó la lectura de libros que normaran su cuerpo y actividades sociales. Ejemplo de lo anterior fueron los diversos manuales de urbanidad y buenas costumbres, los cuales, se complementaron con el catecismo político que les enseñó sus derechos. Por otra parte, se requirió también forjar e inflamar su

53 AHGMP, volumen 14, sección leyes y decretos, f. 34r. 
espíritu con una selección puntual de obras religiosas que les enseñara a ser siervas dóciles.

Los líderes del Ayuntamiento poblano estaban convencidos de la importancia de la instrucción femenina y, a pesar de que en el discurso anterior se habla de la práctica útil que hace referencia a una actividad industrial, el currículum sexuado que se manejó en las escuelas de primeras letras tendió a esclarecer la importancia del gobierno republicano y la constitución mediante los catecismos políticos, las labores de ornato con la enseñanza de bordados, los comportamientos de urbanidad con los libros de buenas costumbres y la formación moral.

Si se atiende entonces a esta simbiosis de conocimientos, no es de extrañarse que, para el periodo Santanista, se estipulara como método de enseñanza oficial el de la escuela lancasteriana, la cual, no solo atendió a solventar los factores de pobreza económica para la enseñanza gratuita de la juventud desvalida, sino que también, era una pedagogía que embonó perfectamente con los criterios del ciudadano libre, pero obediente, y trabajador, pero temeroso de Dios. Sumado a esto, es importante resaltar que fue durante el gobierno de Santa Anna que el culto religioso hacia la Virgen de Guadalupe empapó los discursos y fiestas cívicas poblanas, pues la muy noble y muy leal ciudad de Puebla siguió con puntualidad los decretos que se establecieron desde la capital de la nación.

La formación de las poblanas se enmarcó en un arco cultural forjado por el Ayuntamiento de la ciudad, que se halló plenamente convencido en resaltar la importancia de la virginidad y la maternidad mediante el estandarte de la virgen concepcionista, idea creada y desarrollada tres siglos antes por el Convento de la Purísima Concepción, que en el siglo XIX festejó la confirmación oficial de su existencia gracias a los desplegados teológicos del vaticano mediante el decreto papal de Pío Nono. Así, mientras el convento y el ayuntamiento forjaron el estereotipo 294 concepcionista para las mujeres poblanas, la iglesia católica se encargó de sembrar en sus sermones y rosarios la importancia de la Virgen de Guadalupe. 


\section{Bibliografía}

\section{Fuente primaria}

\section{Archivos}

Archivo Histórico General Municipal de Puebla (AHGMP).

Biblioteca José María Lafragua (BJMLF).

\section{Fuentes secundarias}

Arredondo, María Adelina. Obedecer, servir y resistir: la educación de las mujeres en la historia de México. México: UPN-PORRUA, 2003.

Bastero, Juan Luis. "La inmaculada concepción en los siglos XIX y XX”. Anuario de Historia de la Iglesia No. 4 (2004).

Bautista García, Cecilia Adriana. Hacia la Romanización de la Iglesia Mexicana a fines del siglo XIX. Historia Mexicana Vol. 55 No. 1 (2005).

Berriot, Evelyne. "El discurso de la medicina y la ciencia". En Historia de las mujeres en Occidente, Georges Duby y Michelle Perrot. Madrid: Taurus, 2001.

Connaughton, Brian. "La problemática y óptica historiográfica". En México durante la guerra de Reforma. Iglesia, religión y leyes de reforma (Tomo 1), Coordinado por Brian Connaughton y Celia del Palacio Montiel. Xalapa: Universidad Veracruzana, 2011.

Connaughton, Brian. "De la monarquía a la nación en la América española: las disonancias de la fe". En La Iglesia en Nueva España. Problemas y perspectivas de investigación, coordinado por María de Pilar Martínez López-Cano. México: Universidad Nacional Autónoma de México, Instituto de Investigaciones Históricas, 2010. Connaughton, Brian. "La "Metamorfosis en nuestra nación”. Iglesia y religiosidad en México: 1836-1855”. Revista de Estudios Históricos INAH No. 89 (2019).

Cruz, Salvador. Historia de la educación pública en Puebla 1790-1982. Puebla: BUAP, 1995. 
Espino Martín, Javier. "Latín y Modernidad en la educación femenina: los colegios del Sacré-Coeur entre los siglos XIX y XX”. Nova Tellus Vol. 36 No. 1 (2018).

Escolano Benito, Agustín, Tiempos y espacios para la escuela. Ensayos históricos. Madrid: Biblioteca Nueva, 2000.

Galván Lafarga, Luz Elena. "Historia de mujeres que ingresaron a los estudios superiores, 1876-1940". En Obedecer, servir y resistir: la educación de las mujeres en la historia de México, María Adelina Arredondo. México: UPN-PORRUA, 2003.

García Ugarte, Marta Eugenia y Rosas Salas, Sergio Francisco. "La Iglesia católica en México desde sus historiadores (1960-2010)”, Anuario de historia de la Iglesia Vol. 25 (2016).

Gutiérrez, María del Carmen “La Escuela Normal para profesoras en el Estado de México. Un espacio para la formación de las mujeres, 1891-1910”. En Estudios históricos sobre las mujeres en México, María de Lourdes Herrera Feria. Puebla: BUAP, 2006.

Hunter, Ian. Repensar la escuela. Subjetividad, burocracia y crítica. Barcelona: Ediciones Pomares, 1998.

Lempériére, Annick. Entre Dios y el rey: la república. La ciudad de México de los siglos XVI al XIX. México: Fondo de Cultura Económica, 2013.

López, Oresta. "Las maestras en la historia de la educación en México". Revista Sinéctica Vol. 28 (2006).

Loreto López, Rosalva. "La didáctica de la salvación femenina. La dirección de espíritus y la cultura de lo escrito". En Historias compartidas. Religiosidad y reclusión femenina en España, Portugal y América. Siglos XV-XIX, María Isabel Viforcos Marinas, Rosalva Loreto López. León y Puebla: Universidad de León y BUAP, 2007. Loreto López, Rosalva. Tota Pulchra. Historia del monasterio de la Purísima Concepción de Puebla, siglos XVI-XIX. Puebla: BUAP -Educación y cultura, 2017.

296 Mijangos y González, Pablo. “Clemente de Jesús Munguía y el fracaso de los liberalismos católicos en México (1846-1861)”. En México durante la guerra de Reforma. Iglesia, religión y leyes de reforma 
(Tomo 1), coordinado por Brian Connaughton y Celia del Palacio Montiel. Xalapa: Universidad Veracruzana, 2011.

Pita Pico, Roger. "De niñas escolares a madres y esposas: restricciones a la educación femenina en Colombia durante la temprana vida republicana, 1820-1828”. Revista Interdisciplinaria de Estudios de Género del Colegio de México Vol. 3 No. 5 (2017).

Popkewitz, Thomas y Brennan, Marie. El desafío de Foucault. Discurso, conocimiento y poder en la educación. Barcelona: Ediciones Pomares- Corredor, 2000.

Rosas Salas, Sergio. "De la república católica al estado laico: Iglesia, estado y secularización en México 1824-1914”. Lusitania Sacra: Revista do Centro de Estudios de Historia Eclesiástica No. 25 (2012).

Rosas Salas, Sergio. La iglesia mexicana en tiempos de la impiedad: Francisco Pablo Vázquez 1769-1847. México: COLMICH, BUAP, Eyc, 2015.

Sonet, Martine. “La Educación de una Jóven” en Historia de las mujeres en Occidente, Georges Duby y Michelle Perrot. Madrid: Taurus, 2001.

Staples, Anne. "Una educación para el hogar: México en el siglo XIX". En Obedecer, servir y resistir: la educación de las mujeres en la historia de México, María Adelina Arredondo. México: UPN-PORRUA, 2003.

Tirado Villegas, Gloria A. Hilos para bordar. Acercamientos a las poblanas en el porfiriato. Puebla: Ayuntamiento de Puebla, 2014.

Van Deusen, Nancy. "El cuerpo femenino como texto de la teología mística". En Historias compartidas. Religiosidad y reclusión femenina en España, Portugal y América. Siglos XV-XIX, María Isabel Viforcos Marinas, Rosalva Loreto López. León y Puebla: Universidad de León y BUAP, 2007.

Vásquez Monzón, Olga C. "La mujer religiosa, la mujer ilustrada, la mujer ciudadana: representaciones y prácticas femeninas en algunos periódicos salvadoreños, 1871-1889”. Realidad: Revista de Ciencias Sociales y Humanidades No. 135 (2013). 
Yurén Camarena, María Teresa. “¿Para qué educar a las mujeres? Una reflexión sobre las políticas educativas del siglo XIX”. En Obedecer, servir y resistir: la educación de las mujeres en la historia de México, María Adelina Arredondo. México: UPN-PORRUA, 2003.

\section{Conferencia}

Peña Espinosa, Jesús Joel. Vivir la fé perseguidas: las Agustinas Recoletas de Puebla en los siglos XIX y XX, Museo de Arte Religioso ex Convento de Santa Mónica, Puebla, INAH, 17 de Julio de 2020

Para citar este artículo: Marín Ibarra, Mariana. "Madres, pecadoras y obedientes: la formación religiosa de las poblanas en la primera mitad del siglo XIX mexicano" (Chaco, Argentina, circa 1929-1960)", Historia Caribe Vol. XVI No. 38 (Enero-Junio 2021): 269-298. DOI: https:/ / doi. org/10.15648/hc.38.2021.2821 